\title{
ESCOLA: ESPAÇO DE RESISTÊNCIA NA INTERPRETAÇÃO DAS POLÍTICAS EDUCATIVAS
}

\author{
VANIA FINHOLdT ANGELO LeITE \\ Universidade do Estado do Rio de Janeiro (UERJ), Rio de Janeiro, Rio \\ de Janeiro, Brasil
}

\begin{abstract}
Resumo: Este trabalho aborda o processo de interpretação/tradução das políticas educativas pelos educadores na escola básica de Goiás e do Rio de Janeiro, analisando os ajustamentos secundários realizados por eles nesse processo. Utilizo os conceitos de atuação das políticas (BALL et al., 2016) e o de comunidade de prática (LAVE; WENGER, 1991) para apoiar-me na argumentação. Constatou-se que, em Goiás e na cidade do Rio de Janeiro, os educadores encontraram brechas para resistirem às propostas da política educativa. No primeiro caso, a política por ser mais prescritiva possibilitou ações mais pontuais dos professores no enfrentamento das propostas. No Rio de Janeiro, por ser uma política em fase inicial e menos prescritiva, possibilitou a formação de uma comunidade de prática que fortaleceu o trabalho em equipe.
\end{abstract}

Palavras-chave: Atuação das políticas. Políticas educativas. Processo de ensino.

\section{INTRODUÇÃO}

Este ensaio aborda o processo de interpretação/tradução das políticas educativas pelos educadores na escola básica, analisando os ajustamentos secundários realizados por eles nesse processo. Defendo a ideia de que as políticas não são simplesmente "implementadas", ao contrário, há um processo de interpretação/tradução dos educadores, que é guiado por valores assumidos por eles em relação ao que concebem a respeito do processo de ensino e a desconstrução das desigualdades na escola. Para tanto, utilizarei os conceitos de atuação das políticas (BALL et al., 2016) e o de comunidade de prática (LAVE; WENGER, 1991) para apoiar-me nessa argumentação.

Para Ball et al. (2016), as escolas e os educadores interpretam/traduzem a política de acordo com sua visão educativa, condições materiais, infraestrutura, história de vida e profissional. Quando uma política educativa é proposta, os educadores fazem uma leitura inicial, isto é, a interpretação. Eles verificam o que está em jogo e as consequências de aderir ou não à proposta da política. Nessa ponderação, os atores avaliam se a adesão ou não da política interfere no orçamento da escola, na classificação em um ranking como, por exemplo, o IDEB.

A tradução, por sua vez, se configura como processo de transpor a linguagem da política do contexto da produção do texto para o contexto da prática, como ratifica Ball 
et al. (2016, p. 45), ela "[...] é um processo repetitivo de criar textos institucionais e a colocação desses textos em ação, literalmente, de 'atuação' ". Tanto a interpretação quanto a tradução da política são influenciadas pela posição e o tempo de serviço dos educadores na escola, o cargo que ocupam e suas concepções de educação. Isso irá interferir na leitura que farão da política. Outros aspectos que interferem nesse processo, apontados por Ball et al. (2016), são os seguintes: o contexto material, estrutural e relacional entre os educadores da escola; a história e local da instituição; a cultura profissional e o contexto externo da escola.

Para compreender esse processo, tomo como referência o conceito de policy enactments ou atuação das políticas (BALL et al., 2016), porque ele propicia observar como os educadores e as escolas lidam com as demandas trazidas pelas políticas. É um conceito que se opõe à ideia de implementação de política, de que é um processo de cima para baixo, no qual os educadores simplesmente irão cumprir com as determinações impostas. Isso não ocorre, porque os educadores estão "envolvidos em processos, lutas, negociações sobre o que certas políticas significam, o que poderia ser feito na prática, como essas interpretações poderiam ser construídas e reconstruídas" (BALL et al., 2016, p. 10). Assim, abre-se um espaço entre os textos legais e as ações cotidianas nas quais os educadores podem atuar, reescrever a política. Existe um espaço para interpretação das políticas pelos atores que estão na escola, porque elas não chegam prontas, "muitas vezes, [são] mal pensadas ou mal escritas e são reescritas ou reajustadas" (SPILLANE, 2004; MAGUIRE, 2007 apud BALL et al. 2016, p. 20).

Os educadores podem atuar de duas formas diante das políticas: pela invenção ou pela obediência. Na invenção, os educadores podem usar de sua criatividade e posicionamento em relação à educação para engajar-se ou não na política educativa. $\mathrm{Na}$ atuação pela obediência, os educadores submetem-se à política sendo capturados por ela. Essas duas ações dos educadores em relação à política estão condicionadas as condições objetivas e ao conjunto de dinâmicas "interpretativas" subjetivas (BALL et al., 2016).

Outro conceito que utilizarei é o de comunidade de prática proposto por Lave e Wenger (1991). No caso deste artigo, esse conceito auxiliará na identificação do que uniu os educadores em torno do projeto da escola. Para esses autores, comunidade de prática é a reunião (presencial ou virtual) de um grupo de pessoas que visam o mesmo interesse, ou seja, realizarão práticas específicas como, por exemplo, uma profissão. Essa prática é que define o pertencimento e identidade dessas comunidades. Nelas, as pessoas possuem os mesmos interesses e compartilham competências em determinado assunto. São os próprios membros que negociam, dissolvem seus empreendimentos e definem suas próprias fronteiras. Cabe também aos membros definirem os objetivos e negociarem entre eles as tarefas e se engajam para lidarem com as dificuldades e as inquietações decorrentes da prática (Wenger, 1998). Essas são características que diferem de uma entidade institucional.

Wenger (1998) identificou três dimensões de uma comunidade de prática. A primeira dimensão é a do engajamento mútuo dos participantes, em que eles se juntam para realizar uma tarefa em conjunto. Ao engajarem-se, a diversidade de competência de 
cada membro contribui para a realização dessa tarefa. Cada um faz o que sabe e aprende com o outro que tem mais habilidade, completando os conhecimentos e as ações dos demais da equipe. A segunda dimensão é o empreendimento conjunto definido pelos participantes no processo de constituição de uma CoP, que é (re)negociado constantemente pelos membros, não sendo, portanto, um acordo estático. Nesse empreendimento, a confiança e o respeito estabelecidos entre os membros da CoP são fundamentais para a realização do trabalho conjunto e as trocas de informações. A terceira se refere ao repertório compartilhado de discurso e ação criados pelo empreendimento conjunto que a comunidade constrói com o passar do tempo juntos. No repertório estão incluídos as palavras, as ferramentas, as formas de realizar tarefas, histórias, gestos, símbolos, ações ou conceitos que a comunidade criou ou adotou durante a sua existência.

Os exemplos que serão usados na argumentação fazem parte dos dados de pesquisa de dois grupos: a) um de Goiás - Grupo de Pesquisa Teorias da Educação e Processos Pedagógicos coordenado por José Carlos Libâneo e Raquel A. M. Freitas; b) e o outro do Rio de Janeiro - Grupo de Pesquisa Formação de Professores, Currículo e Cotidiano Escolar - liderado por Maria Inês Marcondes. Os motivos de escolher os dados desses grupos são: I. realizaram pesquisas sobre políticas educativas com lógicas gerencialistas e performativas no período de 2009 a 2017; e II. Adotaram abordagem qualitativa e instrumentos semelhantes de coleta de dados. Esses dados foram coletados em artigos publicados em dois livros (LIBÂNEO; FREITAS, 2018; MARCONDES; CUNHA, 2018). Esses dois grupos se diferenciam em relação ao local, rede e segmentos em que realizaram a pesquisa. $\mathrm{O}$ grupo de Goiás coletou os dados na rede estadual no Ensino fundamental de $5^{\circ}$ ao $9^{\circ}$ ano, e o do Rio de Janeiro no $1^{\circ}$ ao $9^{\circ}$ ano na rede municipal. Outras diferenças serão explicitadas na próxima seção.

Nas duas pesquisas, percebi que o Estado mantém o controle à distância do que ocorre nas escolas por meio de definição de objetivos, de metas e de prestação de contas para cada instituição da rede. Portanto, é regido pelo novo gerencialismo. Por fim, diante do exposto, levanto a questão norteadora: quais ajustamentos secundários os professores e coordenadores fizeram na política educativa em cada rede? No próximo tópico, apresentarei as análises da interpretação/tradução dessas duas redes.

\section{AS PESQUISAS: INTERPRETAÇÃO/TRADUÇÃO DAS POLÍTICAS EDUCATIVAS}

Neste tópico, abordarei alguns dados dos dois grupos de pesquisa, mostrando o processo de interpretação/tradução da política por essas escolas. Percebemos que as instituições investigadas fizeram ajustamentos secundários (BALL et al. 2016) na sua prática pedagógica, currículo e avaliação para que pudessem atender às prescrições da política, adaptando-as aos seus valores. Os professores das duas redes de ensino não compactuam com as propostas educativas, porque, na perspectiva deles, proporcionarão mais desigualdades no processo de ensino dos alunos. Por isso, eles propuseram outras atividades e ações na escola.

O primeiro exemplo de interpretação/tradução que discutirei é a pesquisa do grupo de Libâneo e Freitas (2018, p. 27), pois eles afirmam que as políticas educativas neoliberais propagam um discurso de qualidade educacional, mas elas "não promovem a 
qualidade de educação, ao contrário, são restritivas à promoção do desenvolvimento humano". Acrescento, ainda, que elas incentivam a competição, individualismo e exclusão dentro da escola. Isso ocorre porque, de acordo com os autores, essas políticas propõem um currículo instrumental ou de resultados imediatos que visa ensinar os conteúdos que preparem o educando para atuar no mercado de trabalho. Limita-se aos conteúdos que podem ser medidos em testes padronizados, quantificáveis e métodos de ensino transmissivos. Além das modificações no currículo, Libâneo e Freitas (2018) apontam que a organização do ensino também é afetada, pois todas as ações do professor são voltadas para repassar o conteúdo das "apostilas" e/ou materiais estruturados por agentes externos à escola. O papel do aluno é o de treinar para realizar as provas padronizadas.

Para Libâneo e Freitas (2018), nas escolas tudo gira em torno da obtenção das metas do Índice de Desenvolvimento da Educação Básica (IDEB) e de se manter o ranking elevado, mesmo que os dados tenham que ser distorcidos para alcançar os resultados propostos pela política. Por exemplo, o Projeto Reconhecer, que foi criado pela rede estadual, com intuito de premiar os bons professores (SILVA, 2018). Para Silva (2018, p.136), "os critérios rígidos estabelecidos no Programa Reconhecer não consideram as condições psicológicas e fisiológicas dos docentes, retirando-lhes direitos previstos no Plano de Carreira".

Além disso, a pesquisa de Silva (2018) aponta que as escolas da rede sofreram modificações com as diretrizes, metas e ações organizadas em torno de uma lógica performativa. Uma das ações, nessa direção, foi a criação de um "Período de Intensificação da Aprendizagem (PIA)" (SILVA, 2018, p. 144), com o intuito de melhorar a nota do IDEB e o fluxo escolar. Nesse período, os alunos são reagrupados em turmas para rever algum conteúdo de uma disciplina. Para em seguida, realizar outra avaliação, cuja nota será substituída pela menor nota do bimestre, distorcendo os índices. Assim, adia-se a reprovação e garante a permanência do aluno, consequentemente, melhora-se o IDEB. Os professores entrevistados por Silva $(2018$, p.144) demonstram insatisfação em relação a essa prática: “[...] o aluno falta várias vezes, e isso já é lei não tem que discutir, ele retorna, vem ordens da subsecretaria para elaborar projeto para conter a evasão (se referindo ao PIA). [...] o que está em jogo não é o conhecimento, é aprovar".

Esse professor e também os outros dessa rede estão percebendo que a política educativa não tem favorecido o processo de ensino e aprendizagem dos alunos. Evidente no seguinte depoimento: "os conteúdos apenas existem como algo que precisa ser trabalhado porque que há uma fragmentação na sequência que dificulta a formação de conceitos e, portanto, do pensamento crítico [...]" (SILVA, 2018, p. 142). Apesar de os conteúdos não favorecerem a aprendizagem e o pensamento crítico, os professores encontram uma brecha para fazer de outra maneira como, por exemplo, "se está na semana de Avaliação Dirigida Amostral (ADA), e elas estão em cima, eu dou uma aulinha da ADA, mas procuro sempre voltar para minha sequência e meu conteúdo" (SILVA, 2018, p. 145). Outro professor criou a monitoria como uma forma de atender às dificuldades no processo de aprendizagem dos seus alunos, nas suas palavras: "eu tento fazer essa monitoria dentro da sala, aproveitando os melhores. Infelizmente, o acompanhamento em outro horário foi impossível" (CUNHA et al., 2018, p. 222). 
Esses depoimentos corroboram com Libâneo $(2018$, p. 69) e mostram que o exame padronizado proposto pela secretaria não é capaz de "avaliar adequadamente competências imprescindíveis para a formação humana como a expressão do pensamento por meio da escrita, a formação de conceitos, expressão de emoções, [...]" dentre outros. Nessa direção, Ravitch (2011, p. 257) aponta que aumentar a nota nos testes padronizados não significa uma educação melhor, porque, muitas vezes, esses conteúdos não proporcionaram aos alunos a compreensão dos eventos contemporâneos, bem como "a tomar decisões sobre a sua vida, trabalho e saúde", enfim serem seres humanos melhores.

Para que a escola possa atender a esse objetivo, Libâneo (2018b) defende outra estruturação da escola, pautada em relações pedagógicas baseadas na construção do conhecimento, desenvolvimento intelectual e da formação da personalidade dos alunos. Essa proposta poderá ser efetivada nas escolas, se os professores, como esses demonstraram, saber qual é o seu papel no processo de ensino. Ou seja, que eles proponham ações que favoreçam o processo de aprendizagem de seus alunos, tais como: planejam sequências didáticas para atender ao nível de desenvolvimento dos discentes; criam monitoria e reorganizam a ordem dos conteúdos a serem trabalhados; dentre outras. Esse processo de interpretação/tradução da política é o de invenção, pois esses professores encontraram algumas brechas para que pudessem acompanhar o processo de aprendizagem de seus alunos, buscando diminuir as desigualdades na escola. Embora a política educativa da rede de Goiás tenha utilizado de muitos mecanismos (ADA, PIA, dentre outros) para controlar o trabalho dos professores, mesmo assim, o envolvimento deles e os valores defendidos por eles são fatores que interferem na atuação de cada um diante da política educativa.

Em cada contexto/sociedade, as políticas educativas assumem diferentes configurações, foi o que observei na pesquisa desenvolvida no grupo liderado por Maria Inês Marcondes, na cidade do Rio de Janeiro. A escola interpreta/traduz a política educativa de forma diferente do grupo de Goiás. Dessa forma, a mim não cabe julgar nenhum desses processos de interpretação/tradução. Mas, por outro lado, tenho o privilégio de analisar o que favorece ou não os ajustamentos secundários realizados pelos educadores na política educativa.

A política dessa cidade também está baseada na lógica performativa, focada nos resultados e metas estabelecidas pela Secretaria Municipal de Educação (SME). Além disso, a SME estabeleceu as Orientações Curriculares, os Cadernos de Apoio Pedagógico, as listas de descritores e as avaliações padronizadas. A partir disso, percebe-se uma forte tendência à responsabilização de educadores e gestores pelo desempenho dos alunos, evidentes no estímulo ao desempenho em avaliações padronizadas e competições entre as escolas da rede, por meio de realizações de homenagens e premiações das unidades escolares.

Para essa discussão, selecionei a pesquisa de Leite e Freund (2018) por ser parte dos dados de doutorado da primeira autora. Elas analisaram as estratégias didáticas de formação continuada de uma coordenadora pedagógica com os professores em uma escola da rede municipal do Rio de Janeiro. As autoras observaram que a coordenadora buscou equilibrar a proposta da política educativa imposta pela SME com o projeto da escola. É uma escola que se denomina de Escola de leitores, porque o projeto dessa 
instituição gira em torno da formação de leitores, da autonomia dos educandos e na sua formação cidadã.

A escola está localizada na zona oeste da cidade do Rio de Janeiro, uma área com problemas de violência, classe social de baixo poder econômico, a maioria dos pais semialfabetizados. No entanto, Leite e Freund (2018) observaram que o fato da escola ter um projeto pedagógico no qual todos se mobilizavam para sua realização proporcionou que esses educadores interpretassem/traduzissem a política de forma inventiva (BALL et al. 2016). Isso significa que a escola modificou algumas propostas da política educativa imposta pela SME.

Primeiro, em relação à área de Língua Portuguesa, a escola não se mobilizou para a fabricação de resultados nas provas dessa área, nas quais a cobrança girava em torno das estratégias de leitura. Pelo contrário, as educadoras continuavam desenvolvendo seus projetos literários, porque valorizavam essas atividades e consideravam que, através delas, os alunos seriam bem-sucedidos nas avaliações padronizadas. Leite e Freund (2018, p.77) concluíram que os projetos realizados de forma coletiva e democrática "demonstram [...] ter o potencial de enfrentar as tendências homogeneizantes das políticas [...]".

O trabalho em torno dos projetos fortaleceu o grupo de professores e os fizeram desenvolver uma prática pedagógica que atendesse às necessidades do processo de aprendizagem de seus alunos e não para atender às prescrições da política. A exemplo disso, a coordenadora "levava os professores a refletirem se as aulas estão planejadas de acordo com as necessidades dos alunos. Para que isso ocorresse, era necessário o diagnóstico do professor" (LEITE; FREUND, 2018, p.75). Isso demonstra que a coordenadora estava preocupada com o processo de ensino e não com a performance dos alunos.

Paulatinamente, a SME intensificou a cobrança da escola para que se adequasse ao cumprimento das metas. Por isso, a secretaria vinculou a nota bimestral da escola às atribuídas nas avaliações padronizadas e elaboradas pela secretaria e, com isso, passou a ter um índice para comparar as escolas. Essa "pressão sobre os indivíduos, formalizadas pelas apreciações/avaliações" (BALL, 2002, p.11), proporcionou uma pequena mudança nas reuniões de formação dessa escola. A coordenadora passou a enfocar mais no tema avaliação, mas ainda procurava equilibrar essas discussões com o projeto da escola. Ou seja, ela continuava refletindo com as professoras a respeito das intervenções realizadas por elas com as crianças. A coordenadora não deixou que essa pressão por metas e rankings afetasse a prática de avaliar da escola de leitores. Por isso, ela ainda insistia com as professoras que o fato de as crianças não saírem bem nas provas padronizadas se dava, porque as docentes não faziam intervenções de acordo com o nível de aprendizagem dos alunos (LEITE, 2012).

O trabalho coletivo em torno dos projetos foi outra forma das educadoras resistirem à lógica da competição e comparação entre as escolas. Enquanto que a lógica performativa incute a ideia de um trabalho individual entre os educadores, a escola de leitores buscava equilibrar a proposta educativa da escola com as prescrições da política através do engajamento de todos em torno dos projetos de leitura (LEITE; FREUND, 2018). Embora a divulgação do ranking das escolas tenha afetado um pouco a prática delas, 
mesmo assim, a escola garantia um espaço de formação continuada na escola, discutindo temas escolhidos por elas como, por exemplo: formação de leitores, alfabetização e avaliação dentre outros.

Os educadores da Escola de leitores demonstram não pactuar com a política educativa da SME no que se refere a limitar a prática pedagógica ao treino dos conteúdos cobrados nas avaliações padronizadas. Identifico que elas criaram uma comunidade de prática (LAVE; WENGER, 1998) como forma de manter os valores defendidos por eles em seu projeto pedagógico. Pois, afirmo isso com base na definição de uma comunidade de prática (CoP), na qual as pessoas do grupo "compartilham uma preocupação ou uma paixão por algo que eles fazem e aprendem como fazê-lo melhor quando eles interagem regularmente" (WENGER, 2006, p. 1). Nesse caso, elas estavam engajadas no empreendimento de projetos de leituras no qual cada uma das professoras contribuía com o que sabia e aprendia na interação com outras docentes mais experientes. Essa é uma das características de uma comunidade de prática.

Além do engajamento, percebi outra característica de uma CoP que é o do empreendimento conjunto. Nessa escola, elas buscavam construir coletivamente um projeto coletivo, todas sentiam-se responsáveis nesse propósito. Mas isso não significa que elas têm que concordar com tudo o tempo todo. Era um processo de negociação constante entre elas para a realização desse projeto. Isso ficou evidente em uma das reuniões observadas, na qual algumas professoras queriam realizar uma competição entre as turmas da escola para quem cumprisse o horário, o uso do uniforme, dentre outras atribuições de aluno (LEITE, 2012). No entanto, essa prática da competição entre as turmas não era um consenso entre as professoras. Quanto à 3a dimensão de CoP, as professoras partilharam um repertório de ações que proporcionassem a formação de leitores.

\section{CONSIDERAÇÕES FINAIS}

Retomando a questão norteadora, percebi os seguintes ajustes secundários feitos pelos educadores, buscando seguir os valores defendidos por eles em relação ao processo de ensino, consequentemente, para minimizar as desigualdades no processo de aprendizagem.

Primeiro, os educadores de Goiás tentaram interpretar a política educativa, mantendo uma sequência didática planejada por eles e que atendesse às necessidades do processo de ensino de seus alunos, não seguindo simplesmente a apostila ou materiais enviados pela secretaria. No entanto, eles tiveram poucos espaços para re-organizar a proposta educativa, porque a política tinha uma prescrição forte e intencional das práticas educativas. Isso corrobora com Ball et al. (2016, p.72) ao dizer que "quanto mais forte e claro o imperativo da política, menos 'vazamento' nos e por meio dos processos de atuação".

No caso de Goiás, o contexto externo da política interferiu muito na prática pedagógica dos professores na escola, porque ela buscou direcionar as ações escolares através da definição de metas e diretrizes a serem alcançadas pela escola. Isso gerou muita pressão, desgastes e estresses nos docentes. Mesmo assim, notei nos depoimentos anteriores que os professores interpretaram/traduziram essa proposta tão diretiva, procurando as lacunas para resistirem as determinações externas. Os educadores 
mostravam suas insatisfações e resistências através das críticas que fizeram em relação às fragmentações das sequências propostas pela secretaria, como também propuseram novos planejamentos e insistiram em seguir um sequenciamento didático que favorecesse o processo de aprendizagem do aluno, diminuindo as desigualdades $e$ exclusões internas na escola.

Segundo, na pesquisa da cidade do Rio de Janeiro, a cultura profissional da escola de leitores foi um dos fatores que contribuiu para que os educadores interpretassem/traduzissem a política da forma descrita anteriormente. A saída encontrada por eles foi a de formar uma comunidade de prática, envolver-se com atividades que fortalecessem o trabalho em equipe e o projeto da escola, como forma de enfrentar a competição e o individualismo incentivado na política educativa.

Portanto, retomando a argumentação inicial do ensaio, as políticas não são simplesmente implementadas. Ainda encontram-se educadores que interpretam/traduzem as prescrições reorganizando-as aos propósitos e valores defendidos por eles. Reafirmo que isso é possível, porque eles sabem que o seu papel é a formação humana de seus alunos. Não se limita a formar mão de obra para o mercado de trabalho.

Artigo recebido em: $31 / 10 / 2018$

Aprovado para publicação em: 18/12/2018

\section{SCHOOL: SPACE OF RESISTANCE IN THE INTERPRETATION OF EDUCATIONAL POLICIES}

ABSTRACT: This work deals with the process of interpretation / translation of educational policies by educators in the basic school of Goiás and Rio de Janeiro, analyzing the secondary adjustments made by them in this process. I use the concept of policy action (BALL et al., 2016), and the community of practice (LAVE; WENGER, 1991) to support the argumentation. It was found that in Goiás and the city of Rio de Janeiro, educators found loopholes to resist the proposals of educational policy. In the first case, the policy, because it was more prescriptive, allowed for more punctual actions by teachers in confronting the proposals. Already, in Rio, being an early and less prescriptive policy, it enabled the formation of a community of practice that strengthened teamwork.

KEYWORDS: Policy enactnemts. Educational policies. Teaching process.

\section{ESCUELA: ESPACIO DE RESISTENCIA EM LA INTERPRETACIÓN DE LAS POLÍTICAS EDUCATIVAS}

RESUMEN: Este trabajo aborda el proceso de interpretación / traducción de las políticas educativas por los educadores en la escuela básica de Goiás y Río de Janeiro, analizando los ajustes secundarios realizados por ellos en ese proceso. Uso el concepto de actuación de las políticas (BALL et al., 2016), y el de comunidad de práctica (LAVE; WENGER, 1991) para apoyar en la argumentación. Se constató que en Goiás y en la ciudad de Río de Janeiro, los educadores encontraron brechas para resistir las propuestas de la política educativa. En el primer caso, la política por ser más prescriptiva posibilitó 
LEITE, V. F. A.

acciones más puntuales de los profesores en el enfrentamiento de las propuestas. En Río, por ser una política en fase inicial y menos prescriptiva, posibilitó la formación de una comunidad de práctica que fortaleció el trabajo en equipo.

PALABRAS CLAVE: Acción política Políticas educativas. Proceso de enseñanza.

\section{REFERÊNCIAS}

BALL, S. J. Performatividade, privatização e o pós-estado do bem-estar. Educação e Sociedade, Campinas, São Paulo, v. 25, n.89, p.1105-1126, set./dez. 2004.

BALL, S. J; MAGUIRE, M.; BRAUN, A. Como as escolas fazem as políticas: atuação em escolas secundárias. Ponta Grossa, Paraná: Editora UEPG, 2016.

CUNHA, A. L. A.; OLIVEIRA, N. C. de.; MELO, P. S. Impacto das políticas educacionais nas práticas pedagógicas de professores de ciências. In: LIBÂNEO, José C.; FREITAS, Raquel A. M. da M. Políticas educacionais neoliberais e escola pública: uma qualidade restrita de educação escolar. Goiânia: Editora Espaço Acadêmico, 2018.

LAVE, J.; WENGER, E. Aprendizagem situada: participação periférica legítima. New York: Cambridge University Press, 1991.

LEITE, V. F. A. A atuação da coordenação pedagógica em conjunto com os professores no processo de recontextualização da política oficial no $1^{\circ}$ ano do Ensino Fundamental no Município do Rio de Janeiro. 2012. 160 f. Tese (Doutorado em Educação) - Pontifícia Católica do Rio de Janeiro, Departamento de Educação, Rio de Janeiro, Rio de Janeiro, 2012.

LEITE, V. F. A.; FREUND, C. S. Estratégias didáticas da formação continuada empreendida pelo coordenador pedagógico no contexto da reforma: limites e possibilidades. In: MARCONDES, M. I.; CUNHA, V. G. P. Pesquisa sobre política, currículo e cotidiano escolar. Rio de Janeiro: 7 letras, 2018.

LIBÂNEO, J. C.; FREITAS, R. A. M. da M. Políticas educacionais neoliberais e escola pública: uma qualidade restrita de educação escolar. Goiânia: Editora Espaço Acadêmico, 2018.

LIBÂNEO, J. C.; FREITAS; R. A. M. da M. Políticas educacionais neoliberais e escola: uma qualidade de educação restrita e restritiva. In: LIBÂNEO, J. C.; FREITAS, R. A. M. da M. Políticas educacionais neoliberais e escola pública: uma qualidade restrita de educação escolar. Goiânia: Editora Espaço Acadêmico, 2018b. p.45-88.

MARCONDES, M. I.; CUNHA, V. G. P. Pesquisa sobre política, currículo e cotidiano escolar. Rio de Janeiro: 7 letras, 2018. 
RAVITCH, D. Vida e morte do grande sistema escolar americano: como os testes padronizados e o modelo de mercado ameaçam a educação. Porto Alegre: Sulina, 2011.

SILVA, S. P. Reforma educacional goiana: desdobramento no currículo e nas práticas educativas. In: LIBÂNEO, José C.; FREITAS, Raquel A. M. da M. Políticas educacionais neoliberais e escola pública: uma qualidade restrita de educação escolar. Goiânia: Editora Espaço Acadêmico, 2018. p. 132-151.

WENGER, E. Comunities of Practices: Learning, Meaning, and Identity. New York: Cambridge University Press, 1998.

WENGER, E. Comunities of practice. A brief introduction. 2006. Disponível em: http://www.ewenger.com/theory/. Acesso em: 20 mar. 2016.

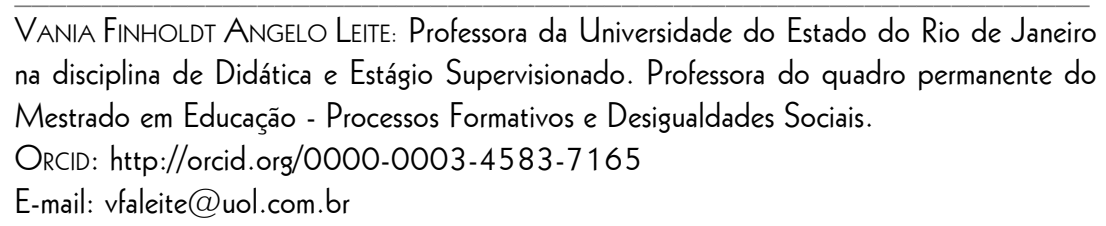

Este periódico utiliza a licença Creative Commons Attribution 3.0, para periódicos de acesso aberto (Open Archives Iniciative - OAI). 